\title{
Preview: 2019 Materials Research Society Spring Meeting \& Exhibit
}

\author{
Phoenix Convention Center, Phoenix, Arizona | Meeting: April 22-26 | Exhibit: April 23-24 \\ mrs.org/spring2019
}

\section{$\mathrm{T}$} he 2019 Materials Research Society (MRS) Spring Meeting \& Exhibit will be held at the Phoenix Convention Center (PCC), April 22-26. The scientific sessions will include many new and developing areas of materials research, as well as some well-established and popular topics. To complement the sessions, tutorials will provide detailed introductions to exciting areas of research, and the exhibit will showcase products and services of interest to the scientific community.

Making up the core of the Meeting are seven topical clusters of the technical program, encompassing 60 symposia. They are grouped as follows:

General Interest: This cluster features the newest LATE NEWS-HOT TOPIC symposium, GI01-Advancing Materials Discovery with Data-Driven Science.

Additional LATE NEWS-HOT TOPIC symposia include QN06 - Emerging Materials for Quantum Information, QN07_Emergent Phenomena in Oxide Quantum Materials, and SM03 - Growing Next-Generation Materials with Synthetic Biology.
Broader Impact: This cluster features one symposium that addresses increasing ethnic and gender diversification in engineering education.

Characterization, Processing and Theory: This cluster features nine symposia dedicated to a wide range of materials and applications. Special focus will be on advanced nanoscale characterization and in situ investigations of materials, novel materials design, and the role of interfaces as well as advances in modeling and simulation across length scales.

Electronics and Photonics: This cluster features 13 symposia divided into two subclusters. One subcluster will focus on soft, stretchable electronics with symposia addressing the fundamentals of the materials systems, assembly and fabrication, applications exemplified through functional circuits, and interfaces with electronic and photonic devices and systems, including considerations for biofriendly electronics. The other subcluster will focus on the latest developments in electronic and photonic devices, plasmonics, metamaterials, phase-change materials, and thermoelectrics. They will also cover new developments in applications involving memory, neuromorphic computing, and advanced approaches for interconnects relevant to the extension of the complementary metal oxide semiconductor roadmap.

Energy and Sustainability: This cluster features 21 symposia that will address the challenges, opportunities, and technologies related to energy materials, devices, and systems. The cluster will comprise subclusters on energy storage, catalysis, alternative energy and fuels, water-energy materials and sustainability, and photovoltaics and energy harvesting. Specific topical areas include perovskites, novel semiconductors, batteries, capacitive devices, fuel cells, electrochemical systems, solar fuels, as well as advanced concepts for materials design, circular economy, and water-energy nexus.

Quantum and Nanomaterials: This cluster features eight symposia dedicated to a wide range of nanoscale science and technologies, including the characterization, properties, and applications of 2D materials, thermal materials and heat transport, as well as quantum information and

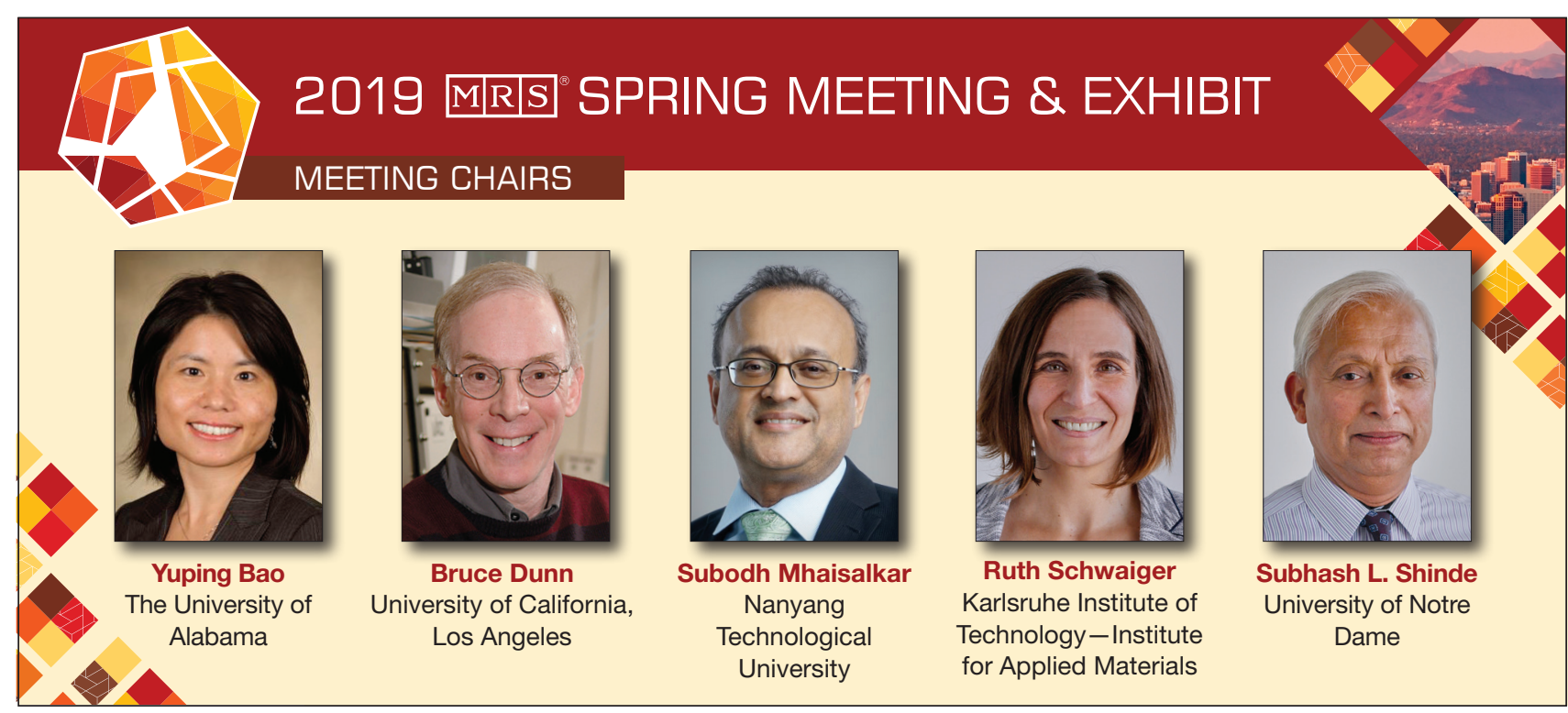


quantum phenomena. Many of the symposia will organize joint sessions to further strengthen the synergies and advance novel materials development.

Soft Materials and Biomaterials: This broad interdisciplinary cluster features seven symposia. Key topics include materials for biological and medical applications, progress in supramolecular nanotheranostics, next-generation materials with synthetic biology, translational materials in medicine- prosthetics, sensors, and smart scaffolds, supramolecular biomaterials for regenerative medicine and drug delivery, nano- and microgels, and bioinspired materials - from basic discovery to biomimicry. This cluster also covers great synergy with bioelectronics covered in the electronics cluster.

Poster sessions will be held in the PCC Exhibit Hall on Tuesday from 2:00-7:00 pm and Wednesday from 11:00 am-7:00 $\mathrm{pm}$. The Meeting chairs will recognize the best presentations each day of the poster sessions. One or more awards of up to $\$ 500$ will be presented based on the posters' technical content, appearance, graphic excellence, and presentation quality.

Symposium X-Frontiers of Materials Research, Tuesday-Thursday, April 23-25, 12:15-1:15 pm, will feature presentations aimed at a broad audience and on topics at the forefront of research in materials science and engineering.

The 2019 MRS Spring Meeting Awards Ceremony will be held on Wednesday, April 24 at 9:00 am. Awards include the Innovation in Materials Characterization Award, MidCareer Researcher Award, MRS Impact Award, Outstanding Young Investigator Award, MRS Postdoctoral Awards, and Graduate Student Awards. The Innovation in Materials Characterization Award presentation directly follows.

MRS will host a Career Fair in Exhibit Hall C on April 23-24, where job seekers can connect with recruiters and explore available career opportunities. Attendees can discuss their qualifications directly with recruiters, participate in mock interviews, and network with employers. Register online and upload your resume at jobs.mrs.org or stop by the Career Fair to access the registration stations.

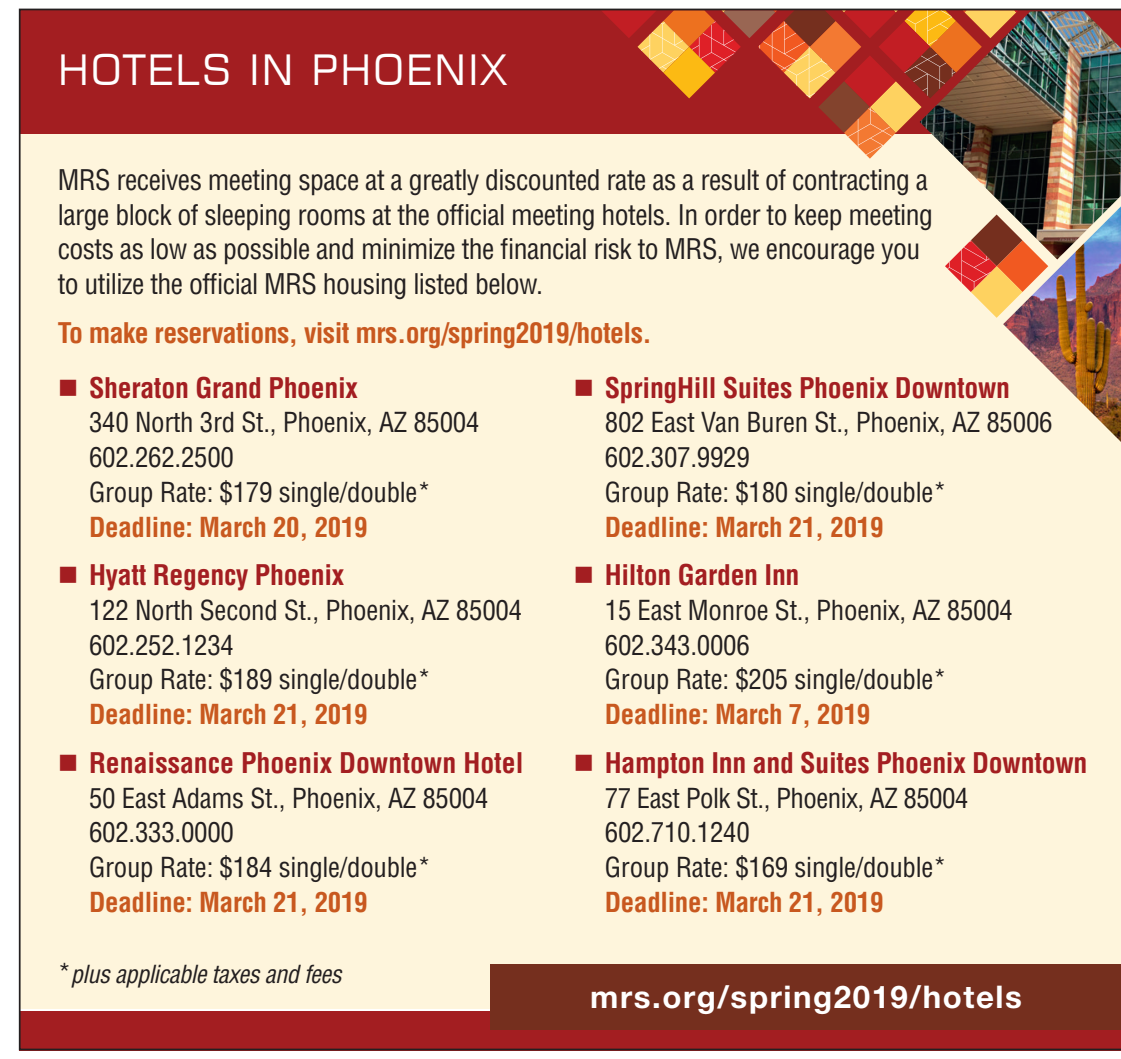

The 2019 MRS Spring Meeting \& Exhibit also features a robust slate of Broader Impact events.

Designing Sustainability into Materials Research Workshop. Many sustainability initiatives are focused on the development of technologies that minimize our carbon footprint and energy use. In this interactive workshop on Monday, April 22, 10:00 am-12:30 pm, participants will learn to expand the definition of sustainability to include aspects that limit sustainable materials development. This workshop is appropriate for materials researchers at all career stages, including faculty and industry researchers, earlycareer professionals, and students. (Preregistration required. Limited seating.)

Communicating Science to NonSpecialists-Science Communication Workshop. The MRS Public Outreach Committee (POC), in collaboration with the Princeton Center for Complex Materials (PCCM), is planning a half-day interactive workshop on Monday, April 22 beginning at 1:00 pm. This session is from the PCCM's Science Communication and Education Network Workshop Series and is a proven NSF-funded model for scientists to engage in public and faceto-face interactions with group activities, discussions, and lectures. All participants will receive feedback. There will be three modules discussing different topics in science. This is an excellent program to aid researchers in fulfilling their Broader Impact criterion for government agency grant proposals. (Preregistration required. Limited seating.)

National Laboratory and User Facilities-How to Get Access for Your Research, on Monday, April 22, 2:005:00 pm, is for students and early-career professionals interested in learning what national laboratories have to offer and how to apply, including practical tips to prepare for using the facility.

Essentials of Getting Your Work Published will be held Monday, April 22 at 3:30 pm in PCC North. Learn the fundamentals of successful scientific publishing from MRS journal editors-in-chief.

The Student, Postdoc \& Industry Mixer will be held Monday, April 22 from 7:00 to 8:00 pm in the Sheraton Hotel. Graduate students and members of MRS University Chapters are invited to attend the reception. 
There will be Research Funding Opportunities sessions on Monday and Tuesday from 5:30-8:00 pm. These sessions provide interaction between government agency presenters and MRS membership. Invited talks will be followed by roundtable question and answer sessions with the individual program managers.

Green Cards for Scientific Researchers will be on Tuesday, April 23 at 2:45 pm. This presentation will cover and compare the criteria for EB-1A classification for foreign nationals of extraordinary ability in the sciences, arts, education, business, or athletics; EB-1B classification for foreign nationals who are outstanding researchers and professors; and the National Interest Waiver (NIW) Category. For more information, visit click4immigration.com.

A Congressional Science and Engineering Program Information Session will be available on Tuesday, April 23, 4:15-5:15 pm for attendees to learn about the MRS/OSA and MRS/TMS Congressional Fellowships and hear from current and former Fellows about their experiences as scientists in the US Senate and House of Representatives.

How to Prepare for Your ABET Accreditation will help materials departments prepare for their ABET (Accreditation Board for Engineering and Technology) visit. The training is on Tuesday, April 23, 7:15-9:30 pm, and the session can be attended without registering for the Meeting. Remote access will be available if unable to attend in person.

Moderated 2050 Panel DiscussionMaterials Needs for Energy Sustainability by 2050: Incentivizing a ZeroWaste Future. Another in a series of the 2050 panel events, co-organized by Symposium ES13 and the MRS Focus on Sustainability Subcommittee, is planned for Tuesday evening. The program will convene top experts to discuss scientific, technological, and sociological complexities relating to energy, the environment, and sustainability. This event will include audience Q\&A as well as real-time interactive audience polling.

Materials Voice will be available on-site Tuesday and Wednesday in the Exhibit Hall for members to help in support of sustained federal research funding. It is quick and easy to send letters on funding and current policy issues that are important to the materials research community.

Prior to the 2019 MRS Spring Meeting, teams of students curated or developed their own materials datasets for the inaugural Open Data Challenge competition. Winners will be announced at the Open Data Challenge Awards Presentation on Wednesday, April 24, 3:00-3:30 pm.

Real-Life Challenges and Opportunities in Sustainable Product Design Seminar. Learn how to incorporate sustainability principles into research in a more comprehensive way while considering real-world applications in product design and manufacturing. This seminar will be held on Wednesday, April 24, 7:30-8:30 pm, and is aimed at materials researchers of all career stages.

Learn more about Materials Science Research Aboard the International Space Station during a presentation on Wednesday, April 24 from 2:00-2:30 pm.

Students are invited to participate in the MRS PowerPoint Karaoke and

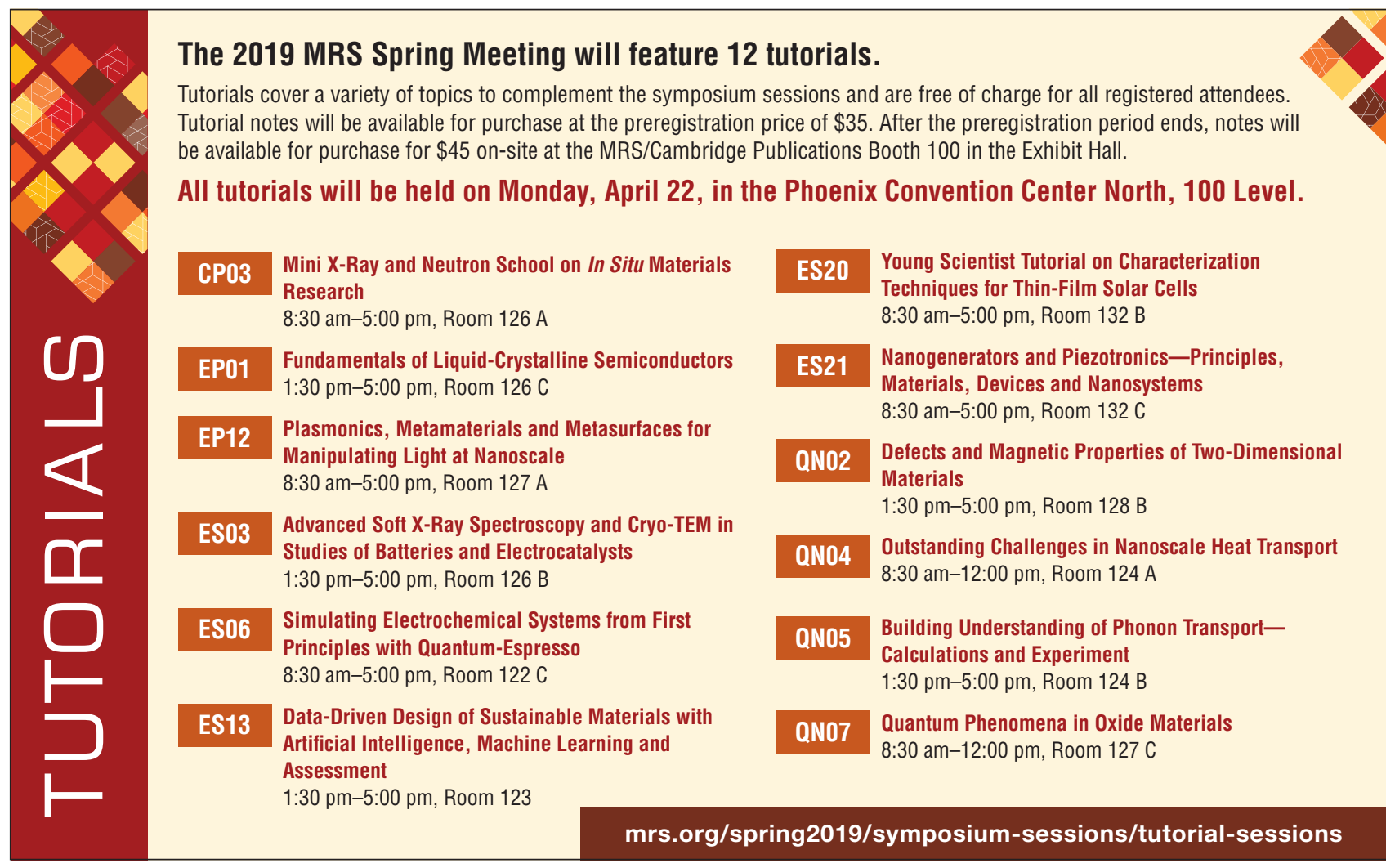


Networking Reception on Wednesday, April 24, 7:30-9:00 pm. This new event is for attendees who want to showcase their research in an interactive and fun way. More information is available on the 2019 MRS Spring Meeting website.

The MRS/Cambridge University Press Publications Booth 100 will be featured in the Exhibit Hall. Stop by to learn about the MRS Publications Portfolio and receive $20 \%$ off all book purchases.

The popular Science as Art competition is open to all registered Meeting attendees. Multiple first-place and secondplace awards of $\$ 400$ and $\$ 200$, respectively, will be presented at the Meeting. Guidelines are listed on the 2019 MRS Spring Meeting website.

The deadline to preregister for the 2019 MRS Spring Meeting is April 5 (5:00 pm ET). International travelers

\begin{tabular}{|l|c|c|}
\hline \multicolumn{2}{|c|}{2019 MRS SPRING MEETING REGISTRATION RATES } \\
\hline Meeting Registration & $\begin{array}{c}\text { PREREGISTRATION } \\
\text { before 5:00 pm (ET) } \\
\text { April 5, 2019 }\end{array}$ & $\begin{array}{c}\text { ON-SITE REGISTRATION } \\
\text { after 5:00 pm (ET) } \\
\text { April 5, 2019 }\end{array}$ \\
\hline Meeting Registration with MRS Member Discount & $\$ 715$ & $\$ 845$ \\
\hline Student Registration (Proof of student status required.) & $\$ 565$ & $\$ 705$ \\
\hline Student Registration with MRS Member Discount & $\$ 130$ & $\$ 200$ \\
\hline Retired & $\$ 190$ & $\$ 160$ \\
\hline Unemployed & $\$ 160$ & $\$ 215$ \\
\hline
\end{tabular}

2019 MRS Spring Meeting registrations include MRS Membership from July 1, 2019 to June 30, 2020.

are reminded to begin the visa process early. For additional information on the Spring Meeting, contact MRS Member Services, e-mail info@mrs.org and tel. 724-779-3003.
The MRS website can be accessed for updated information on confirmed talks and details on special events, information on obtaining a visa, and preregistration at.mrs.org/spring2019.

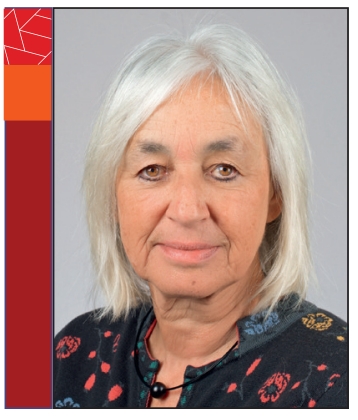

\section{Van Swygenhoven-Moens to present Kavli lecture during 2019 MRS Spring Meeting plenary session}

$\mathrm{H}$ elena Van Swygenhoven-Moens will present The Fred Kavli Distinguished Lectureship in Materials Science on Tuesday, April 23. She is a professor at the École Polytechnique Fédérale de Lausanne (EPFL) in the Materials Science Institute; she also leads the Neutrons and X-rays for Mechanics of Materials Laboratory and heads the Photons for Engineering and Manufacturing Research Group at the Paul Scherrer Institute in Switzerland.

Helena's presentation is titled, "Synchrotron Light to Investigate Materials In Operando." Synchrotron radiation beams are now sufficiently bright and detectors are sufficiently fast that scattering and x-ray absorption data can be followed in real time for a material under action. With the use of synchrotron radiation, high-resolution computer-aided tomographic microscopy is possible. One can now look at the formation of pores, microcracks, or gas bubbles during the interaction of a material with an external environment.

Helena studied physics at the Vrije Universiteit Brussels and received her $\mathrm{PhD}$ degree in physics from the Central Jury in Belgium. After a professional break for motherhood, she continued her career with a Marie-Heim Vögtlin Grant from the Swiss National Science Foundation. Helena is a Fellow of the Materials Research Society, elected member of the Royal Academy of Science of Belgium, and an advanced grant holder from the European Research Council. For many years, she chaired the International Board of the International Committee of Strength of Materials, was a member of the Scientific Advisory Committee of the European Spallation Source, was on the peer review panel of Diamond, and was on the beamline review panels of ESRF. Helena also serves on the engineering expert panel of the National Science Foundation Flanders and on expert panels of the ERC.

The core of her work is the development and use of in situ experiments at synchrotron and neutron facilities, with the aim to follow a material's microstructure in operando and to provide synergies between experiments and computational modeling. Helena's research focuses on the link between synthesis and microstructure, including laser-based additive manufacturing methods and the connection between microstructure and mechanical behavior of a variety of materials, ranging from nanostructured materials for watch components, superelastic alloys for medical applications, and advanced steels and lightweight alloys for structural applications. Through her ERC advanced grant (MULTIAX), Helena addresses non-proportional multiaxial straining covering the gap between our current knowledge of mechanical behavior derived from uniaxial deformation tests and the engineering reality of applications and processing routes. 